\title{
O Sistema Aqüífero Urucuia
}

\section{Márcia Tereza Pantoja Gaspar ${ }^{1}$ \& José Eloi Guimarães Campos ${ }^{2}$}

\begin{abstract}
Resumo O Sistema Aqüífero Urucuia (SAU) representa uma associação de aqüíferos que ocorrem em arenitos flúvio-eólicos do Grupo Urucuia, Neocretáceo da bacia Sanfranciscana, que compõe a maior parte da cobertura fanerozóica do Cráton do São Francisco. A área efetiva do SAU estende-se por $76.000 \mathrm{~km}^{2}$ desde o sul do Piauí até o noroeste de Minas Gerais, tendo sua maior expressão em área relacionada ao oeste do estado da Bahia. Apresenta um eixo divisor longitudinal que separa o fluxo subterrâneo para o sentido oeste (bacia hidrográfica do Tocantins) e o sentido leste (bacia hidrográfica do São Francisco). A oeste do divisor há um aumento progressivo da profundidade da superfície potenciométrica, caracterizada pela presença de níveis estáticos profundos. Os dados disponíveis admitem a proposição de quatro subtipos de aqǘferos no SAU: aqüífero livre regional; aqǘfero suspenso local; aqüífero confinado ou semiconfinado e aqüífero livre profundo. A existência de níveis silicificados, variações granulométricas nos arenitos e a posição geográfica e espacial são os principais parâmetros controladores da presença e/ou predominância desses subtipos de aqǘf́re dentro do sistema. Os parâmetros hidrodinâmicos obtidos são: capacidade específica dos poços de até $17,2 \mathrm{~m} / \mathrm{h} / \mathrm{m}$, transmissividade variando de $10^{-2}$ a $10^{-5} \mathrm{~m}^{2} / \mathrm{s}$, condutividade hidráulica de $10^{-5}$ a $10^{-7} \mathrm{~m} / \mathrm{s}$, coeficiente de armazenamento da ordem de $10^{-4}$ (aqüífero confinado) até $10^{-1}$ (aqüífero livre). As reservas de água permanentes obtidas são de $3,77 \cdot 10^{12} \mathrm{~m}^{3}$, enquanto que as reservas reguladoras são de aproximadamente $30,78 \cdot 10^{9} \mathrm{~m}^{3} / \mathrm{ano}$.
\end{abstract}

Palavras-chaves: Sistema Aqüífero Urucuia, subtipos de aqüíferos, parâmetros hidrodinâmicos, reservas hídricas.

\begin{abstract}
The Urucuia Aquifer. The Urucuia Aquifer System (UAS) represents an association of groundwater reservoirs developed in Upper Cretaceous fluvial aeolian sandstones of the Urucuia Group, Sanfranciscana Basin, the main Phanerozoic coverage of the São Francisco craton. This aquifer system extends for about 76,000 $\mathrm{km}^{2}$ from the south of Piauí state up to the northwest region of Minas Gerais state, but the major expression in area is related to the west of Bahia state. It presents a longitudinal axis that separates the groundwater regional flow to west (Tocantins hydrographic basin) and east (São Francisco basin). Westward of the divisor there is a fast fall of the potentiometric surface, characterized by the presence of deep static levels. The available data allow defining four subtypes of aquifers in the UAS: regional unconfined aquifer, local perched aquifer, confined aquifer, and deep unconfined aquifer. The presence of silicified levels, grain size variations of the sandstones and the geographic and space position are the main controlling parameters of the presence of these subtypes in the system. The hydrodynamic parameters are: specific capacity of the wells up to 17.2 $\mathrm{m}^{3} / \mathrm{h} / \mathrm{m}$, transmissivity of $10^{-2}$ to $10^{-5} \mathrm{~m}^{2} / \mathrm{s}$, hydraulic conductivity of $10^{-5}$ to $10^{-7} \mathrm{~m} / \mathrm{s}$, storage coefficient of $10^{-4}$ (confined aquifer) to $10^{-1}$ (unconfined aquifer). The permanent water reserve has been estimated of $3.77 \cdot 10^{12}$ $\mathrm{m}^{3}$, while the regulating reserves are about $30.78 \cdot 10^{9} \mathrm{~m}^{3} / \mathrm{year}$.
\end{abstract}

Keywords: Urucuia Aquifer System, aquifers subtypes, hydrodynamics parameters, groundwater reserves.

INTRODUÇÃO A demanda crescente de água para as necessidades básicas do homem, na indústria e, sobretudo para produção de alimentos, tem buscado na água subterrânea uma alternativa mais econômica e de melhor qualidade, substitutiva ao uso da água superficial, a qual está mais vulnerável às atividades potencialmente contaminantes dos grandes centros urbanos e no meio rural.

Essa crescente demanda tem despertado o interesse de pesquisadores e órgãos governamentais frente às necessidades de dados técnicos para embasar as ações administrativas do Sistema Nacional de Gerenciamento de Recursos Hídricos - SINGREH. As outor- gas de direito de uso de recursos hídricos está entre os instrumentos previstos pela Política Nacional de Recursos Hídricos (Lei $N^{\circ}$ 9.433/97) que mais necessitam de informações técnicas.

Na região do oeste do estado da Bahia a água subterrânea tem sido progressivamente procurada como fonte de abastecimento, haja vista a baixa densidade de drenagem da região e a crescente demanda de água para o suprimento das sedes de fazendas, vilarejos e projetos de irrigação. O órgão governamental de gestão de recursos hídricos do estado da Bahia, a Superintendência de Recursos Hídricos da Bahia (SRH-BA), tem concedido números crescentes de outorgas de uso da água

1 - Pós-Graduanda no Instituto de Geociências, Universidade de Brasília, Brasília (DF), Brasil. E-mail: marciatpg@yahoo.com.br

2 - Instituto de Geociências, Universidade de Brasília, Brasília (DF), Brasil. E-mail: eloi@unb.br 
subterrânea.

Esse número crescente de concessão de outorgas de direitos de uso da água subterrânea, segundo Silva et al. (2005), ocorre pelo fato de que alguns rios da região já atingiram o limite legal máximo outorgável, não havendo, portanto, disponibilidade para novas emissões de outorgas de águas superficiais, o que ocasiona uma maior procura pela água subterrânea. Essa procura crescente é justificável também devido ao aumento de áreas de culturas irrigadas e pelas adversidades climáticas sofridas pela região, prejudicando a produtividade das lavouras.

O Sistema Aqüífero Urucuia representa o principal manancial subterrâneo do oeste baiano. Sua importância estratégica remete-se, não somente pelas crescentes demandas de água, mas também pela sua função de regulador das vazões dos afluentes da margem esquerda do médio rio São Francisco; e pela alimentação de nascentes de tributários da margem direita do rio Tocantins, na borda ocidental da Serra Geral de Goiás.

Apesar de sua importância, os estudos realizados no âmbito desse aqüífero têm enfoque local, tendo sido desenvolvidos pela SRH-BA e Universidade Federal da Bahia (UFBA) em bacias hidrográficas específicas. Esses estudos pilotos buscaram obter informações técnicas que servissem de base para a concessão de outorgas e com isso racionalizar o uso da água para irrigação. Esses estudos apresentam informações sobre a qualidade de água, hidrogeologia e estudos hidrológicos (Aquino et al. 2002; Aquino et al. 2003, Santana et al.2002, Silva et al. 2002, Ramos \& Silva 2002).

A ocupação dessa região consistiu de uma progressiva e sistemática supressão do Cerrado, em detrimento da instalação de extensas lavouras de monoculturas. Esse quadro de ocupação e manejo do solo levanta preocupação com relação à sustentabilidade da área de recarga do Sistema Aqüífero Urucuia.

Dessa forma, este trabalho busca apresentar os resultados de uma pesquisa de caráter regional no sistema, com a caracterização dos subtipos de aqüíferos existentes no sistema, seus parâmetros hidrodinâmicos, espessuras, áreas de distribuição e estimativas de reservas hídricas totais.

Os procedimentos e metodologia utilizados para a obtenção dos resultados incluíram: delimitação da área do aqüífero por meio da avaliação do mapa geológico da região; obtenção dos parâmetros hidrodinâmicos e condições de fluxo por meio da avaliação de perfis de poços tubulares profundos, ensaios de bombeamento; estimativa da espessura das rochas por intermédio de levantamento geofísico preliminar; determinação da espessura saturada estimada com base nos resultados da pesquisa de Amorim Junior (2003) realizados na região e avaliação das condições da área de recarga do sistema aqüífero, a partir dos diferentes tipos de solos e formas de ocupação da superfície.

LOCALIZAÇÃO O Sistema Aqǘfero Urucuia ocorre principalmente na região do oeste do estado da Bahia, estendendo-se desde o extremo sul do Maranhão e Piauí, até o extremo noroeste de Minas Gerais. Seus limites meridionais são balizados a oeste pelo limite da Serra Geral de Goiás, desde a região nordeste de Goiás até o sudeste de Tocantins; e, a leste na altura das sedes dos municípios de Barreiras (BA), Correntina (BA), Cocos (BA), Formosa do Rio Preto (BA) e Gilbués (PI) (Fig.1).

\section{DEFINIÇÃO DO SISTEMA AQUÍFERO URU-}

CUIA O termo Sistema Aqüífero Urucuia é proposto como denominação para o conjunto de aqüíferos que ocorrem no domínio do Grupo Urucuia, abrangendo a sub-bacia Urucuia definida por Campos \& Dardenne (1997) como a parte setentrional da compartimentação da bacia Sanfranciscana, que corresponde à maior parte da cobertura fanerozóica do Cráton do São Francisco.

Esse sistema enquadra-se na província hidrogeológica São Francisco, é do tipo intergranular, composto por uma unidade geológica sedimentar, disposta na forma de um espesso tabuleiro, constituída de quartzo arenitos e arenitos feldspáticos eólicos, bem selecionados, com presença de níveis silicificados, e em menor proporção níveis conglomeráticos.

Em quase toda a sua extensão o Sistema Aqüífero Urucuia está mapeado como sobreposto ao conjunto de rochas pelito-carbonáticas do Grupo Bambuí, nos estados da Bahia, Goiás e Minas Gerais (Fig. 2), o qual constitui o sistema cárstico-fissural Bambuí. Na parte norte repousa sobre rochas sedimentares da Bacia do Parnaíba, e também diretamente sobre o embasamento granito-gnáissico, as quais compõem respectivamente os sistemas aqüíferos Poti-Piauí/Serra Grande/Cabeças e Cristalino.

A área de abrangência do Sistema Aqüífero Urucuia inclui, grosso modo, a mesma área de extensão das rochas do Grupo Urucuia. Essa porção da Bacia Sanfranciscana representa a maior expressão em volume e área contínua, que ocorre no oeste da Bahia, correspondendo a toda sua porção de arenitos a norte do rio Carinhanha, visto que ao sul as ocorrências das rochas do Grupo Urucuia são descontínuas e menos espessas. Esse montante corresponderia a aproximadamente $86.000 \mathrm{~km}^{2}$. No entanto, a área efetiva do sistema aqüífero, corresponde àquela onde a unidade aqüífera, desempenha as funções armazenadora, reguladora e filtro, e nesse caso a poligonal é sensivelmente menor que a extensão total da unidade geológica.

A delimitação proposta como área efetiva do sistema exclui regiões onde não há armazenamento de água na unidade ou esse armazenamento é muito restrito, de forma que não há o desempenho da função reguladora das vazões das drenagens superficiais ou não há o desempenho da função reservatório. Essa área estende-se por cerca de $76.000 \mathrm{~km}^{2}$ na região do oeste da Bahia e sudeste do Tocantins (Fig. 3). Os poços representados no mapa da figura 3 constituem o cadastro utilizado no trabalho, que inclui informações coletadas em campo e cedidos por empresas de perfuração na região e empresas governamentais.

Nas regiões excluídas da área efetiva desse sistema aqüífero a produção dos poços perfurados remete- 


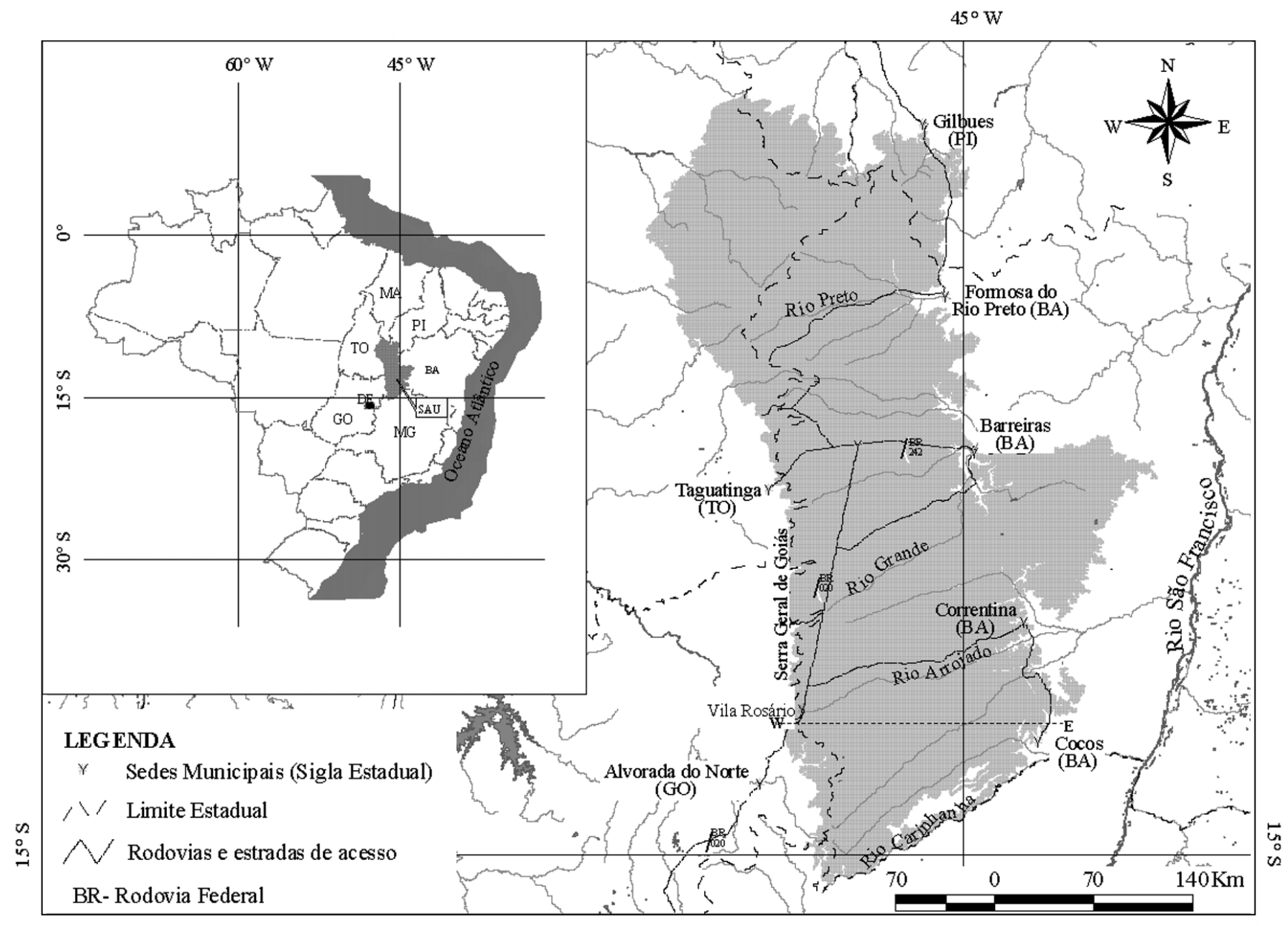

$45^{\circ} \mathrm{W}$

Figura 1 - Mapa de localização do Sistema Aqüifero Urucuia.

W

$\mathbf{E}$

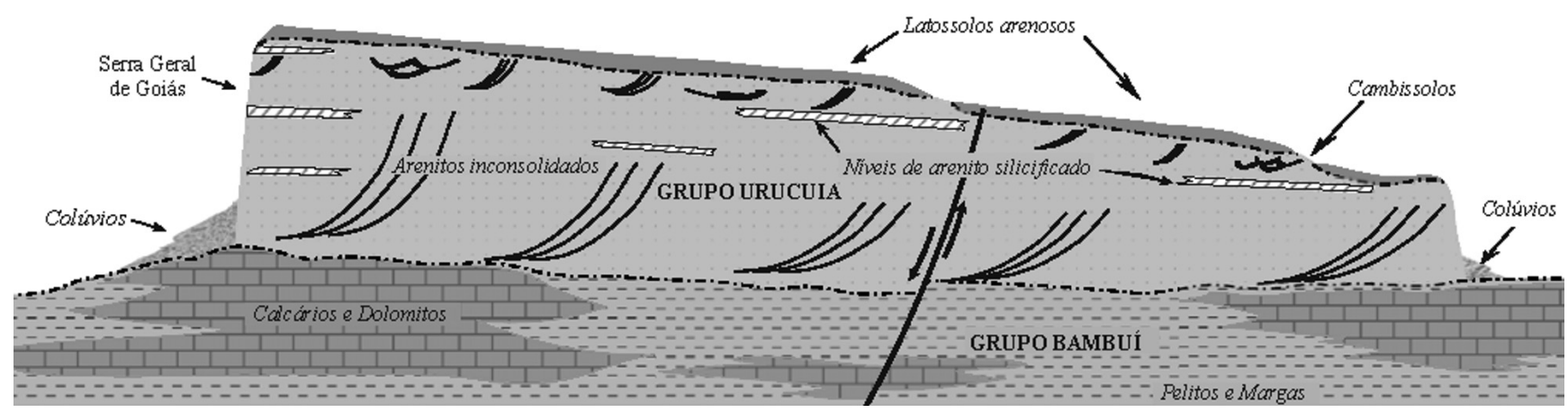

LEGENDA

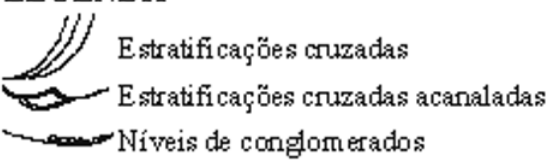

Figura 2 - Perfil leste-oeste esquemático do contexto geológico do Sistema Aqüifero Urucuia no oeste da Bahia. Localização do perfil indicada na figura 1.

se à explotação de águas subterrâneas armazenadas nos sistemas cárstico-fissural Bambuí e cristalino. Nesse contexto os arenitos do Grupo Urucuia estão presen- tes em perfis construtivos de poços de outros sistemas aqǘ́feros e mesmo que com espessuras restritas, compõem apenas suas zonas não saturadas. 


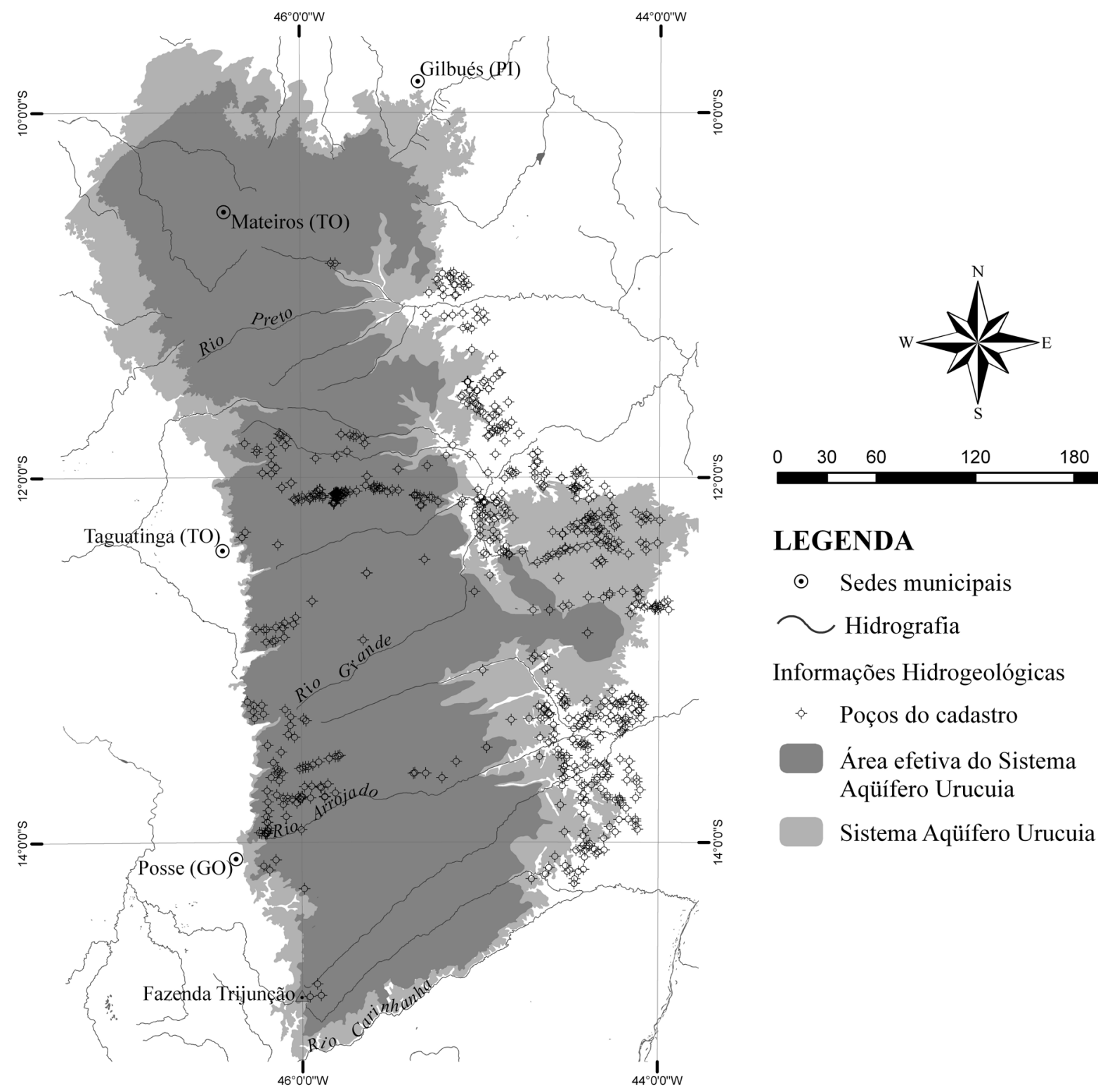

Figura 3 - Área efetiva do Sistema Aqüifero Urucuia, com representação dos poços do cadastro utilizados nesta pesquisa.

No limite oeste de sua área efetiva o Sistema Aqüífero Urucuia exibe um eixo longitudinal divisor do fluxo subterrâneo, que separa o sentido do fluxo regional do sistema para leste e para oeste (Fig. 4).

A presença do eixo divisor de fluxo subterrâneo atribui a esse sistema aqǘfero uma assimetria entre as bacias hidrográfica e hidrogeológica. Nesse contexto uma área delimitada por qualquer bacia hidrológica comporta duas bacias hidrogeológicas que constituem um mesmo sistema aqüífero. A bacia hidrogeológica leste (oriental) contribui com fluxo de base para a alimentação da rede de drenagem pertencente à bacia hidrográfica do São Francisco, enquanto que a bacia hidrogeológica oeste (ocidental) contribui para os cursos superficiais que alimentam a Bacia do rio Tocantins.
O posicionamento aproximado desse eixo divisor de fluxo foi delineado com base nas informações dos levantamentos geofísicos feitos por Amorim Junior (2003), Amorim Junior \& Lima (2003), assim como pela observação dos níveis estáticos dos poços cadastrados na região.

Essa divisão regional do fluxo subterrâneo é devida à rápida depleção da superfície potenciométrica vinculada à feição fisiográfica caracterizada pela Serra Geral de Goiás que determina intensa drenança por intermédio das nascentes em geral situadas na base da quebra de relevo.

A oeste do eixo divisor os níveis estáticos são mais profundos, atingindo cerca de 180 metros na parte meridional do aqüífero, como atestado em poços da Companhia de Engenharia Rural da Bahia (CERB) que 


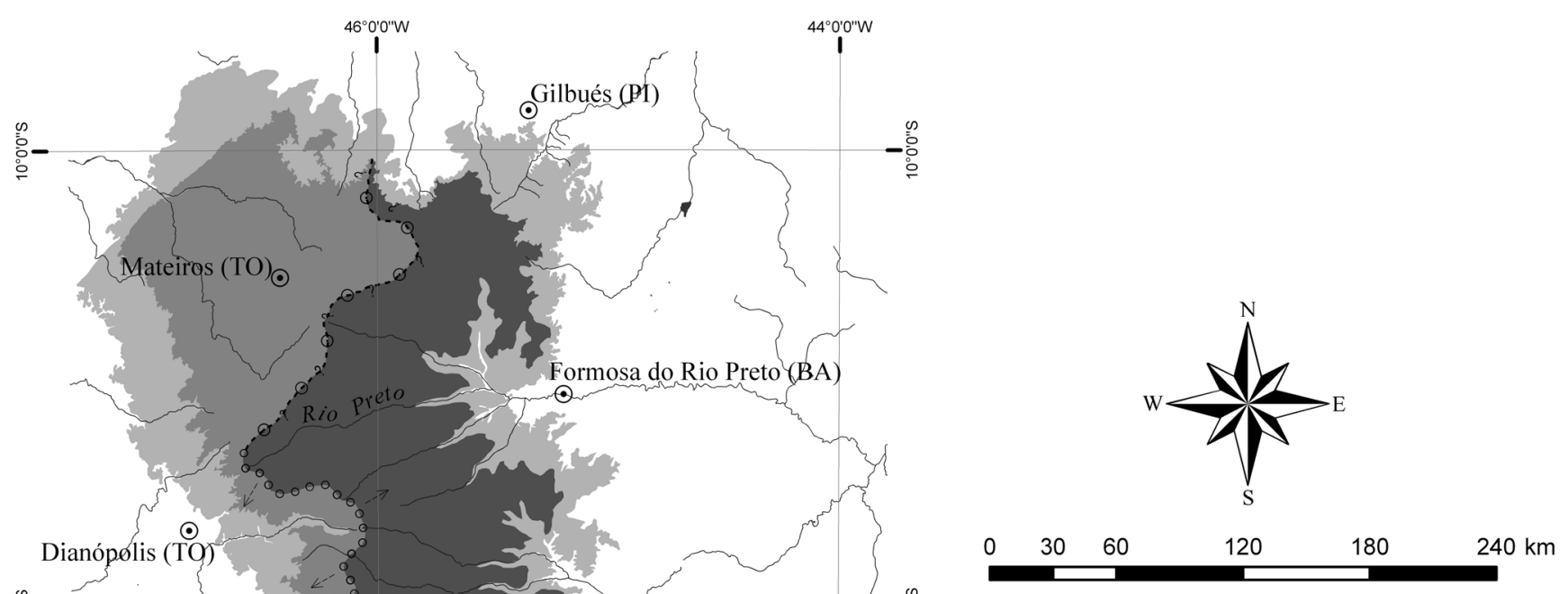

\section{LEGENDA}

$\odot \quad$ Sedes municipais

$\frown$ Hidrografia

\section{Informações Hidrogeológicas}

$\rightarrow$ Fluxo subterrâneo inferido

$0^{\circ} \circ_{\circ} \circ$ Eixo divisor confirmado

๑. - . Eixo divisor inferido

Sistema Aqüífero Urucuia (SAU)

Área Efetiva do Sistema Aqüífero Urucuia

Bacia hidrogeológica SAU-E

Bacia hidrogeológica SAU-W

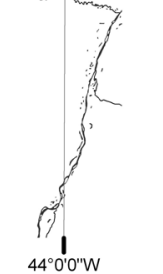

Figura 4 - Eixo divisor de fluxo subterrâneo no Sistema Aqüífero Urucuia.

abastecem a Vila Rosário. Na parte norte alguns poços perfurados pela CERB também confirmaram tal separação do fluxo, com poços de cerca de 200 metros de profundidade perfurados próximo da divisa entre Barreiras e Taguatinga (TO) que não chegaram a alcançar o nível d'água.

A espessura saturada do sistema aqüífero varia desde 80 a 460 metros, sendo que a oeste do eixo divisor de fluxo diminui progressivamente até atingir a base da Serra Geral de Goiás, onde surgem nascentes que alimentam os rios afluentes da Bacia do rio Tocantins.

Seu processo de recarga ocorre por infiltração da água das chuvas nas áreas de chapada, com relevo plano e elevado, onde ocorrem espessos latossolos de textura média e arenosa e onde as alturas pluviométricas médias apresentam os maiores valores (isoietas normalmente superiores a $1.000 \mathrm{~mm}$ por ano). Essa morfologia do relevo é de fundamental importância para o reabaste- cimento do aqüífero. Entretanto nessa área está instalada a grande parte das áreas agricultáveis da região, que comprometem o processo de recarga devido à compactação provocada pelo manejo dos solos (Fig. 5).

Ensaios de infiltração nos latossolos revelaram valores médios de condutividade hidráulica vertical (Kv) em torno de $10^{-4} \mathrm{~m} / \mathrm{s}$ em superfície e $10^{-6} \mathrm{~m} / \mathrm{s}$ em sub-superfície. Valores menores de cerca de $10^{-7} \mathrm{~m} / \mathrm{s}$ foram obtidos em ensaios realizados em pastos, estradas não-pavimentadas, áreas de reflorestamento e de culturas de soja ou em perfil de solo com textura argilosa ou com indícios de compactação.

\section{SUBTIPOS DE AQUÍFEROS E CONDIÇÕES DE} CIRCULAÇÃO O Sistema Aqǘifero Urucuia observado sob o ponto de vista geológico e regional, apresenta-se como um manancial subterrâneo homogêneo e isotrópico. Entretanto, ainda que as rochas do Grupo 


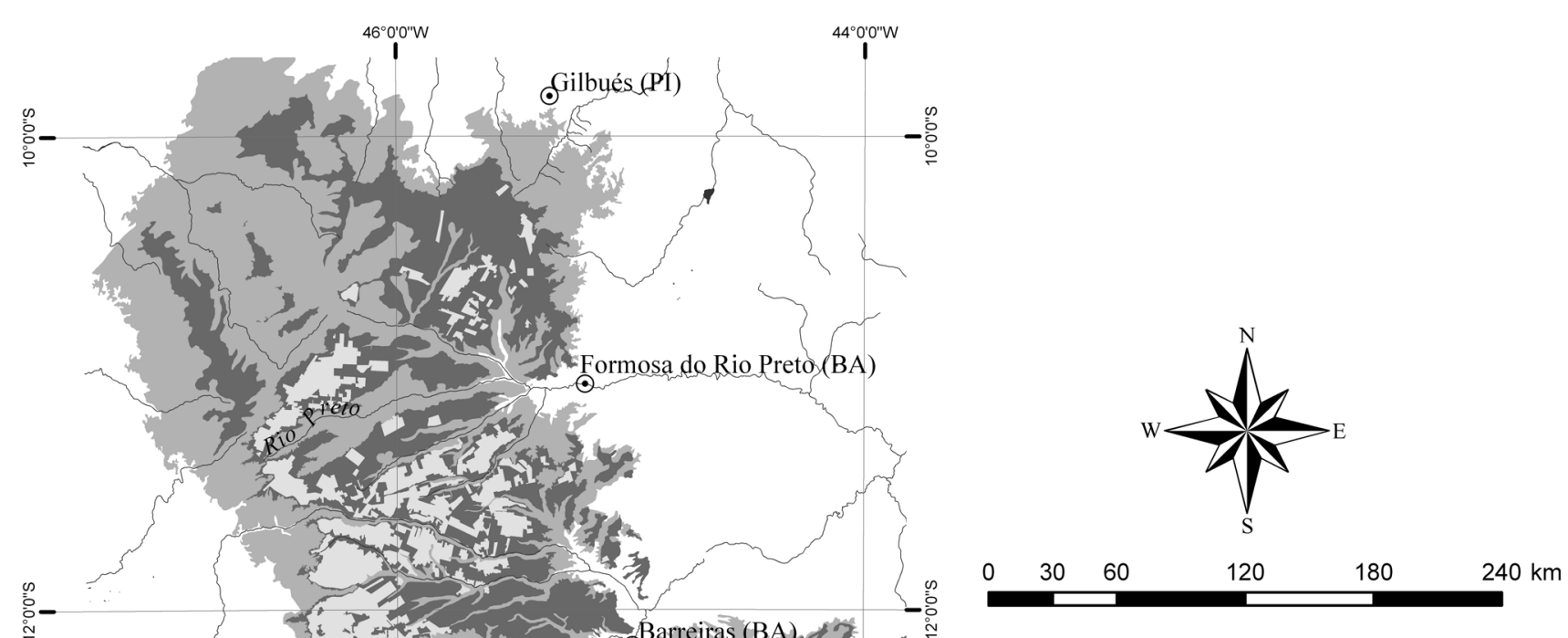

\section{LEGENDA}

$\odot \quad$ Sedes municipais

$\frown$ Hidrografia

\section{Informações Hidrogeológicas}

Sistema Aqüífero Urucuia (SAU)

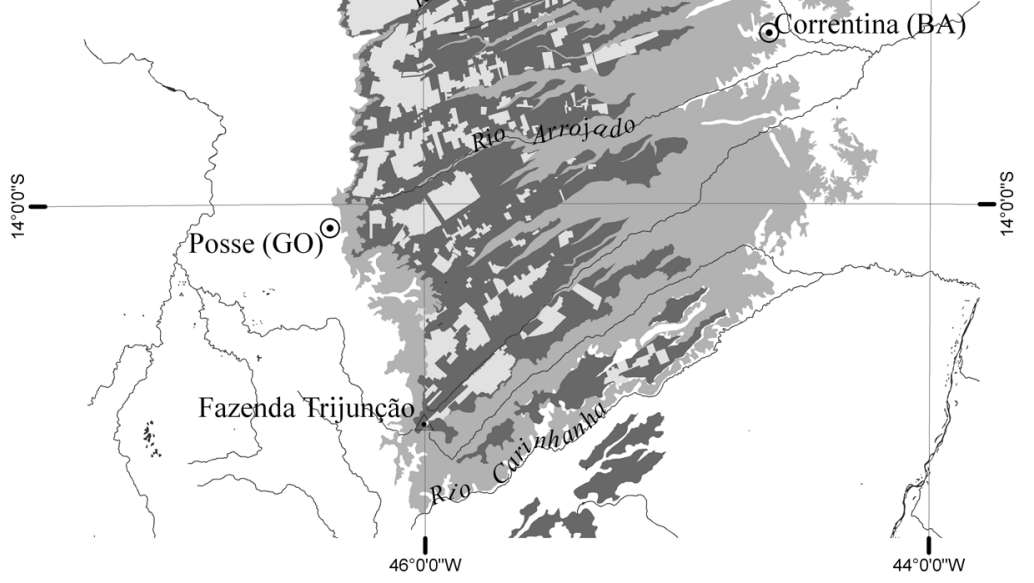

\section{Área de Recarga do SAU}

Área de recarga preservada (boa condição de infiltração)

Área de recarga comprometida pela agricultura

Figura 5 - Mapa de áreas de recarga do Sistema Aqüifero Urucuia e áreas de recarga comprometidas pelo manejo do solo na agricultura até o ano de 2000.

Urucuia componham uma unidade relativamente homogênea e com pouca variedade de litotipos; pequenas e restritas variações faciológicas nessa unidade conferem ao sistema aqüífero, importantes mudanças hidrodinâmicas, permitindo-se diferenciar subtipos de aqüíferos.

A presença de níveis silicificados e sua posição estratigráfica, as variações granulométricas nos arenitos e a profundidade das superfícies potenciométricas são os principais parâmetros controladores da existência e/ou predominância de um ou de outro subtipo de aqüífero dentro do sistema.

As informações dos poços perfurados na região disponíveis subsidiaram grande parte dessa subdivisão, que admite quatro subtipos de aqüíferos: aqüífero livre regional; aqüífero suspenso local; aqüífero confinado ou semiconfinado e aqüífero livre profundo.
Esses subtipos de aqüíferos estão distribuídos de forma diferenciada na região. Sua delimitação preliminar está apresentada de forma esquemática na figura 6 .

Aqüífero livre regional Consiste de um aqüífero amplo, em termos de distribuição espacial na área. Apresenta nível estático variável, e é normalmente explotado por meio de poços tubulares de cerca de 100 metros de profundidade; esses comumente situados nas sedes das fazendas, onde a água subterrânea é utilizada essencialmente para o abastecimento doméstico e como insumo na diluição e aplicação de agrotóxicos nas lavouras.

Esse tipo de aqüífero representa a maior unidade hidrogeológica, dentro do Sistema Aqüífero Urucuia, e normalmente sobrepõe-se aos demais subtipos. Seu fluxo de base mantém a perenidade e a elevada vazão espe- 


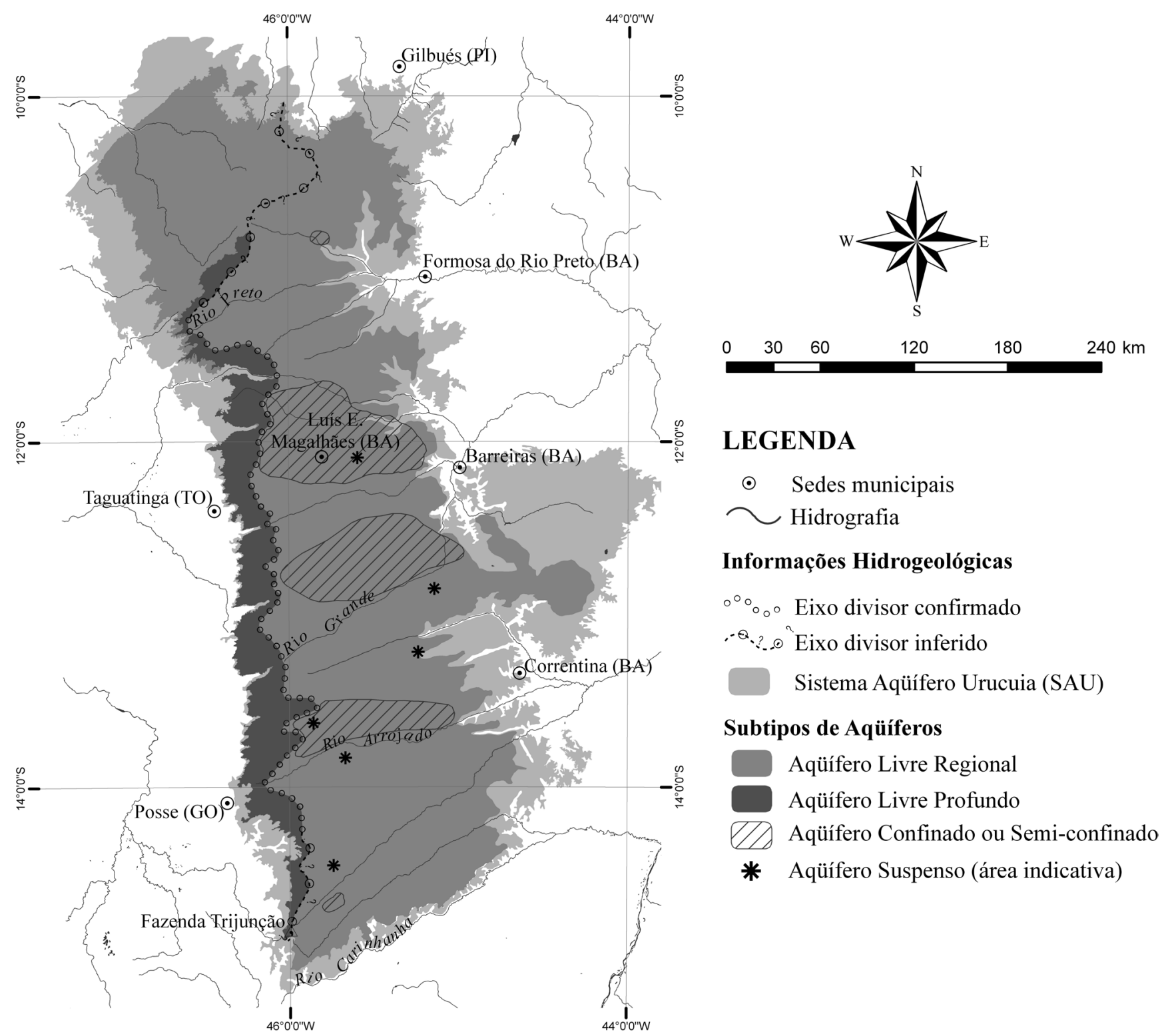

Figura 6 - Mapa de delimitação espacial preliminar dos subtipos de aqüiferos do Sistema Aqüifero Urucuia.

cífica da rede de drenagem da região do extremo oeste baiano, que por sua vez contribui para a regularização da vazão do médio rio São Francisco no período de recessão das chuvas. A vazão específica dos rios dessa bacia é controlada pela alta eficiência desse subtipo de aqüífero, que apresenta sistemas locais e regionais de fluxo e águas de excelente qualidade e pouco mineralizadas.

Aqüífero suspenso local Constitui um subtipo de aqüífero desenvolvido em função da presença de níveis silicificados rasos e de extensão limitada. Esses níveis funcionam como aquitardes, retardando a drenagem vertical da água, o que permite o acúmulo de água e o estabelecimento de uma zona saturada, provavelmente temporária, acima do nível d'água regional. Podem desse modo, dispor-se sobre outros subtipos dentro do sistema regional.
Os níveis silicificados podem ser observados em afloramentos nos vales dos rios que recortam a chapada ou ao longo da Serra Geral de Goiás, apresentam espessuras de 3 a 15 metros e foram interpretados por Campos (1996) como paleo-superfícies freáticas relacionadas ao sistema deposicional desértico responsável pela deposição do Grupo Urucuia.

Segundo Geo Brasil (2002), esse tipo de aqüífero é muito freqüente na topografia de planaltos ou chapadas arenosas do Brasil, tais como na Chapada do Araripe (fronteira entre os estados do Ceará, Pernambuco, Piauí), do Grupo Urucuia (fronteira dos estados da Bahia, Goiás, Tocantins, Minas Gerais) e no Grupo Barreiras, recobrimento arenoso que ocorre ao longo do litoral brasileiro, do Amapá ao estado do Espírito Santo.

Martins et al. (1993) citaram a presença de "aqüíferos suspensos temporários" identificados na área 
da Fazenda Jatobá, localizada na Bacia do rio Arrojado, parte sul da área. Os autores associaram a presença desse tipo de aqüífero na área com um adensamento da vegetação em superfície, sendo descartada a hipótese de variações da fertilidade nos solos analisados.

Sua distribuição ocorre de forma irregular na região, tendo sido apontado no mapa da figura 5 apenas pelas indicações conhecidas das ocorrências desse subtipo na área.

Aqüífero confinado ou semiconfinado A condição de artesianismo desse subtipo de aqǘ́fero é controlada dentro do sistema pela presença de níveis silicificados em maiores profundidades, uma vez que a presença de vários níveis silicificados é comum no perfil dos poços em diferentes posições estratigráficas.

Esses níveis podem funcionar como aquitardes quando ocorrem com a presença de níveis silicificados fraturados, permitindo uma drenagem vertical lenta de água da camada superior para as camadas em maiores profundidades, ou até como aqüífugos. Schuster et al. (2002) atestaram a ocorrência desse subtipo de aqǘf́re por meio de estudo de poços localizados em afluente do rio Grande.

A maioria dos poços tubulares profundos utilizados em pivôs explota água desse subtipo de aqüífero. Exemplos são comuns na região de Luis Eduardo Magalhães (BA), nas bacias dos rios Grande e Arrojado, e na parte norte, no município de Formosa do Rio Preto.

Os níveis potenciométricos nesse subtipo de aqüífero são bastante variáveis e atingem profundidades da ordem de 7 a 70 metros.

Aqüífero livre profundo $\mathrm{O}$ contexto desse aqüífero inclui a bacia hidrogeológica oriental, a oeste do eixo divisor do fluxo do Sistema Aqǘf́re Urucuia. Os poços perfurados nesse aqüífero apresentam superfície potenciométrica não confinada, em sua maior parte, mais profunda que 100 metros.

A superfície potenciométrica nesse contexto tem um aumento progressivo da profundidade, na direção do limite físico da Serra Geral de Goiás. Sua descarga sob condição de elevado gradiente hidráulico determina um sistema de fluxo relativamente rápido que alimenta os rios da região cárstica de Goiás e Tocantins.

Descrições de perfis construtivos de poços nesse subtipo aqüífero não mostraram a presença de níveis silicificados em profundidade, ou mostraram apenas níveis pouco espessos e isolados, indicando que se trata de camadas descontínuas lateralmente, que não têm funcionalidade como camada confinante.

A disposição espacial dos quatro subtipos de aqüíferos dentro do Sistema Aqüífero Urucuia está apresentada em dois perfis esquemáticos na figura 7. O perfil leste-oeste exibe o contexto dos subtipos aqüífero livre regional (I) e aqüífero livre profundo (IV), enquanto que o perfil norte-sul apresenta a disposição espacial dos subtipos aqüífero suspenso local (II) e aqüifero confinado ou semiconfinado (III).

PARÂMETROS HIDRODINÂMICOS Os parâmetros dimensionais dos subtipos de aqüíferos foram obtidos pela interpretação de dados de ensaios de bombeamento com o auxílio do software Aquifer Test Pro ${ }^{\circledR}$, da Waterloo Hydrogeologic Inc. A caracterização hidrodinâmica desses subtipos de aqüíferos baseou-se na utilização de informações disponíveis de poços existentes na região.

Nos trabalhos de campo foram cadastrados mais de 104 poços tubulares de diferentes profundidades,

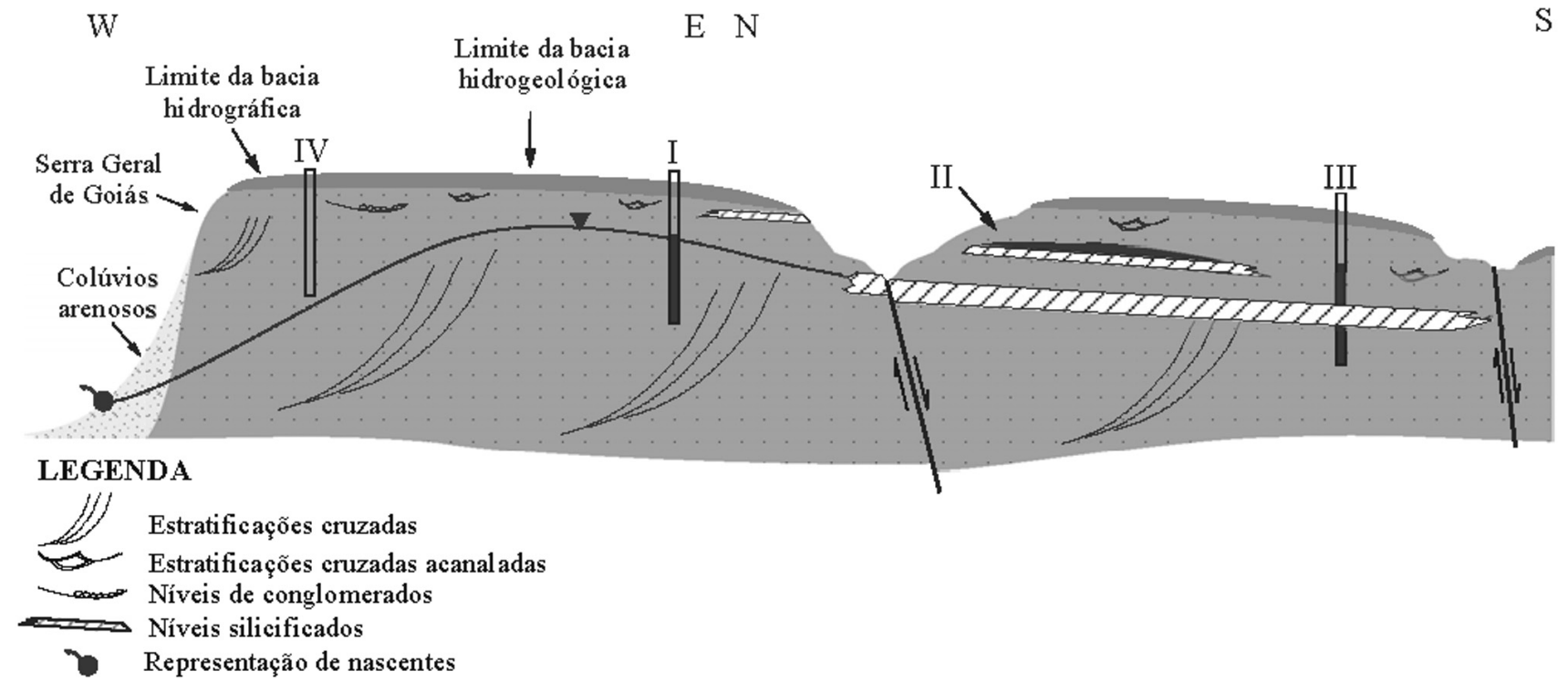

Figura 7 - Modelo esquemático dos subtipos de aqüiferos presentes no Sistema Aqüifero Urucuia (SAU). Perfil composto de uma seção EW e NS. Linha tracejada representa a superfície potenciométrica regional. 
e cerca de 260 poços foram obtidos dos cadastros da Companhia de Engenharia Rural da Bahia (CERB), da Superintendência de Recursos Hídricos da Bahia (SRHBA) e empresas de perfuração como Mauerberg Poços Artesianos Ltda. e a Fuad Rassi. Entretanto, poucos apresentam informações de ensaio de bombeamento.

Os dados disponíveis permitiram uma caracterização preliminar para os subtipos: aqüifero livre regional, aqüifero livre profundo e aqüifero semiconfinado. Apesar de restritos, os dados utilizados foram considerados consistentes e de boa qualidade, quando confrontados os resultados dos parâmetros obtidos com as informações descritivas dos perfis geológicos.

A tabela 1 relaciona os parâmetros obtidos por meio da interpretação dos dados com o método de Neuman (1975) para os subtipos livres e Cooper \& Jacob (1946) para o subtipo confinado.

Os valores de condutividade hidráulica $(\mathrm{K})$, de transmissividade (T) e do coeficiente de armazenamento (S) obtidos para o aqüífero confinado ou semiconfinado são semelhantes àqueles obtidos por outros autores, como Schuster et al. (2002), Schuster (2003) e Nascimento (2003).

É importante salientar que todos os poços até então construídos na região são parcialmente penetrantes e que esse atributo foi levado em consideração durante a modelagem para a determinação dos dados hidrodinâmicos para os vários subtipos considerados.

RESERVAS HÍDRICAS O cálculo das reservas hídricas para o Sistema Aqüífero Urucuia neste trabalho pretende propor uma estimativa preliminar do volume de água armazenado nessas rochas, com vistas a avaliar a potencialidade desse sistema e auxiliar em seu processo de gestão. Portanto, os parâmetros como área do sistema (A), oscilação anual do nível estático $(\Delta \mathrm{h})$,

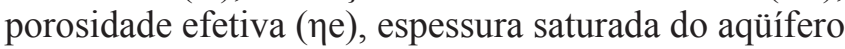
(b), utilizados para o cálculo das reservas são valores médios, obtidos de cadastros da CERB, estudos da SRH-BA, estudos geofísicos e informações de campo.

A área considerada para os cálculos das reservas inclui a área efetiva proposta neste trabalho, que totaliza $76.000 \mathrm{~km}^{2}$.

As reservas permanentes de água $(\mathrm{Rp})$ são da ordem de $3,77 \cdot 10^{12} \mathrm{~m}^{3}$, considerando espessuras saturadas médias de 260 e 340 metros para os aqüíferos livres profundo e regional, respectivamente. A porosidade efetiva de $15 \%$ foi adotada por analogia com sedimentos eólicos similares (Araújo et al. 1995) e é considerada mínima uma vez que, a maior parte da seção estratigráfica do Grupo Urucuia não apresenta qualquer tipo de cimentação e se encontra não litificado. Para o cálculo da reserva permanente considerou-se o volume de saturação dos aqüíferos livres, e uma estimativa do volume de água sob pressão nas áreas delimitadas como aqüíferos semiconfinados ou confinados, considerando uma carga hidráulica de confinamento média de 7 metros.

As reservas reguladoras $(\mathrm{Rr})$ do Sistema Aqüífero Urucuia calculadas com base numa oscilação do nível estático $(\Delta \mathrm{h})$ da ordem de 2,7 metros e $\eta \mathrm{e}=15 \%$ foram estimadas em $30,78 \cdot 10^{9} \mathrm{~m}^{3} / \mathrm{ano}$, que representa o

Tabela 1 - Parâmetros hidrodinâmicos obtidos em poços do Sistema Aqüifero Urucuia

\begin{tabular}{|c|c|c|c|c|}
\hline Aqüífero Parâmetro & $K(m / s)$ & $T\left(m^{2} / s\right)$ & $S$ & $Q / s\left(m^{3} / h / m\right)$ \\
\hline \multirow{2}{*}{ Livre regional } & $2,4 \cdot 10^{-7}$ & $4,9 \cdot 10^{-5}$ & - & 0,46 \\
\hline & $1,3 \cdot 10^{-6}$ & $2,7 \cdot 10^{-4}$ & - & 2,70 \\
\hline Aqüífero livre profundo & $3,9 \cdot 10^{-6}$ & $1,4 \cdot 10^{-3}$ & - & 13,1 \\
\hline \multirow{3}{*}{$\begin{array}{l}\text { Aqüífero confinado ou } \\
\text { semiconfinado }\end{array}$} & $2,55 \cdot 10^{-5}$ & $8,91 \cdot 10^{-3}$ & $1,01 \cdot 10^{-4}$ & 13,1 \\
\hline & $6,4 \cdot 10^{-5}$ & $2,5 \cdot 10^{-2}$ & $1,4 \cdot 10^{-4}$ & 12,35 \\
\hline & $3,8 \cdot 10^{-5}$ & $1,9 \cdot 10^{-2}$ & $1,8 \cdot 10^{-4}$ & 15,18 \\
\hline $\begin{array}{l}\text { Dados obtidos por outros } \\
\text { autores }\end{array}$ & $K(m / s)$ & $T\left(m^{2} / s\right)$ & $S$ & Aqüífero \\
\hline \multirow{2}{*}{ Schuster et al. (2002) } & $1,00 \cdot 10^{-4}$ & $1,61 \cdot 10^{-2}$ & $2,6 \cdot 10^{-4}$ & \multirow{2}{*}{$\begin{array}{c}\text { Aqüífero } \\
\text { semiconfinado }\end{array}$} \\
\hline & $1,08 \cdot 10^{-4}$ & $1,63 \cdot 10^{-2}$ & $1,5 \cdot 10^{-4}$ & \\
\hline \multirow{2}{*}{ Nascimento (2003) } & $4,05 \cdot 10^{-3}$ & $1,52 \cdot 10^{-2}$ & $7,5 \cdot 10^{-4}$ & \multirow{2}{*}{$\begin{array}{c}\text { Aqüífero } \\
\text { semiconfinado }\end{array}$} \\
\hline & $4,11 \cdot 10^{-3}$ & $1,69 \cdot 10^{-2}$ & $3,0 \cdot 10^{-4}$ & \\
\hline Schuster (2003) & $1,61 \cdot 10^{-2}$ & - & $2,74 \cdot 10^{-4}$ & $\begin{array}{c}\text { Aqüífero } \\
\text { semiconfinado }\end{array}$ \\
\hline
\end{tabular}


potencial renovado anualmente pela recarga direta das chuvas.

CONSIDERAÇÕES FINAIS As características e potencialidades apresentadas conferem ao Sistema Aqüífero Urucuia uma fonte estratégica de água para abastecimento público e projetos de irrigação. Esse aqüífero regional merece atenção especial em função de sua ampla importância como regulador das vazões do rio São Francisco no período de recessão das precipitações.

Nas regiões de recarga mais importantes deve ser dada atenção especial na gestão do sistema, principalmente com relação ao risco de poluição, nas áreas de uso agrícola intensivo e zona não saturada pouco profunda e ao risco de sobrexplotação, pois as demandas para irrigação são muito elevadas.

As condições de infiltração são primordiais para a garantia da recarga do sistema aqüífero subjacente. A compactação foi a principal conseqüência observada resultante de intervenções antrópicas referentes às principais atividades desenvolvidas na região (agricultura e pecuária) incluindo o preparo dos solos para o cultivo, retirada da vegetação natural, construção de vias de acesso e estradas não-pavimentadas entre as lavouras, tráfego de máquinas pesadas e formação de áreas de pastagem. Essa compactação é qualitativamente representada pelo aumento do volume de água escoada na superfície do terreno durante o período chuvoso, e foi constatada a partir de mudanças das condições de infiltração da água nos solos, materializadas pela redução dos valores de condutividade hidráulica vertical desses solos, notadamente na parte superficial dos solos.

A identificação de um eixo divisor de fluxo subterrâneo na parte oeste da área dá-se provavelmente devido à presença de um limite físico da unidade aqüífera, ou seja, nessa região o Grupo Urucuia, que forma uma escarpa que compõe a Serra Geral de Goiás, com desnível médio de mais de 200 metros.

$\mathrm{O}$ declínio progressivo da espessura saturada na direção oeste é provavelmente ocasionado pela ausência de camadas confinantes ou menos permeáveis que seriam responsáveis pela retenção da água a menores profundidades. O local exato da posição desse eixo divisor de fluxo subterrâneo provavelmente é variável devido à flutuação sazonal do nível d'água. Sua posição deve representar um equilíbrio hidrodinâmico entre o sistema aqüífero, os fatores climáticos, suas unidades limítrofes e as condições de fluxo regional.

A delimitação espacial dos quatro subtipos de aqüíferos identificados no sistema é preliminar e deve provavelmente ser refinada à medida que forem ampliadas as informações cadastrais de poços tubulares (níveis estáticos, perfis litológicos e perfis construtivos).

Os parâmetros hidrodinâmicos, da mesma forma, são passíveis de otimização, à medida que forem disponibilizadas mais informações de ensaios de bombeamentos em um maior número de poços e com critérios mais exigentes.

As ações de gestão em toda a região do oeste do estado da Bahia devem objetivar:

- o incentivo ao plantio direto, visando minimizar os efeitos da compactação dos solos na área de recarga;

- a exigência da manutenção das reservas legais das fazendas da região;

- a emissão de outorgas de direito de uso da água em todos os poços, com vistas a obter informações sobre os aqüíferos;

- o estímulo ao aproveitamento das águas da chuva, para utilização na aplicação de agrotóxicos, sobretudo nas sedes das fazendas no extremo oeste da área do SAU, onde os níveis estáticos são profundos, e - o monitoramento da qualidade e a evolução dos níveis dos vários subtipos de aqüíferos.

A continuidade dos trabalhos no Sistema Aqüífero Urucuia em âmbito regional deve ser encorajada, para ampliar o conhecimento das feições gerais e melhorar a caracterização dos modelos conceituais dos subtipos e deve contemplar estudos isotópicos, com vistas à datação das águas; caracterização da vulnerabilidade e risco à contaminação, e definição do volume explotável dentro de uma ótica sustentável de explotação de recursos hídricos subterrâneos.

Agradecimentos Os autores expressam seus agradecimentos a Deus; ao Conselho Nacional de Desenvolvimento Científico e Tecnológico $\left(\mathrm{CNPq}\right.$ - processo ${ }^{\circ}$ 4725752003-1); à Companhia de Engenharia Rural da Bahia (CERB) e à Superintendência de Recursos Hídricos da Bahia (SRH-BA) pelo fornecimento de informações de poços na área; às empresas de construção de poços Mauerberg Poços Artesianos e Fuad Rassi; e ao geólogo André Cadamuro por sua dedicação e auxílio na confecção das figuras.

\section{Referências}

Amorim Junior V. 2003. Avaliação Hidrogeológica do aqüífero Urucuia na Bacia do rio das Fêmeas usando IP-Resistividade. Dissertação de Mestrado, Instituto de Geociências, Universidade Federal da Bahia, 82 p.

Amorim Junior V. \& Lima O.A.L. 2003. Aqüífero Urucuia: uma avaliação hidrogeológica integrando resistividade e polarização induzida no domínio do tempo. In: International Congress of the Brazilian Geophysical Society, 8,
Rio de Janeiro, Anais.

Aquino R.F. de, Nascimento K.R.F., Rodrigues Z.R., Vieira C., Maia P.H.P. \& Costa A.B. 2003. Caracterização hidrogeoquímica e isotópica das águas superficiais e subterrâneas do oeste baiano - Bacia do rio das Fêmeas - Bahia. In: ABRH, Simpósio Brasileiro de Recursos Hídricos, 15, Curitiba, CD-ROM.

Aquino R.F. de, Silva F.F., Schuster H.D.M., Batista L.H.G. 
\& Urasaki F.Y.A. 2002. Aspectos Hidroquímicos e da Qualidade da Água Superficial e Subterrânea do Oeste Baiano - Sub-Bacia do rio do Cachorro - Bahia. In: ABRH, Simpósio de Recursos Hídricos do Nordeste, 6, Maceió, CD-ROM.

Araújo L.M., França A.B. \& Potter P.E. 1995. Aqüifero gigante do Mercosul no Brasil, Argentina, Paraguai e Uruguai: Mapas hidrogeológicos das formações Botucatu, Pirambóia, Rosário do Sul, Buena Vista, Misiones e Tacuarembó. UFPR/Petrobras, $16 \mathrm{p}$.

Campos J.E.G. 1996. Estratigrafia, Sedimentação, Evolução Tectônica e Geologia do Diamante da porção centronorte da bacia Sanfranciscana. Tese de Doutorado, Instituto de Geociências, Universidade de Brasília, 204 p.

Campos J.E. \& Dardenne M.A. 1997. Origem e Evolução Tectônica da Bacia Sanfranciscana. Rev. Bras. Geoc., 27(3):283-294.

Cooper H.H. \& Jacob C.E. 1946. A generalized graphical method for evaluating formation constants an summarizing well field history. Am. Geophys. Union Trans., 27:526-534.

GEO Brasil 2002. O Estado do Meio Ambiente no Brasil, p. 23-216. In: Thereza Christina Carvalho Santos \& João Batista Drummond Câmara (orgs.) Perspectivas do Meio Ambiente no Brasil. Brasília, Edições IBAMA, 440 p.

Martins E.S., Lopes Assad M.L.R.C. \& Campos J.E.G. 1993. Comportamento de solos desenvolvidos de arenito Urucuia. In: Congresso Brasileiro de Ciência do Solo, 24, Goiânia, Anais, v.1, p. 171.

Nascimento K.R.F. (Coord.) 2003. Uso Conjunto das Águas Superficiais e Subterrâneas da Sub-Bacia do Rio das Fêmeas - BA. Relatório Final (Subprojeto 3.2 - Projeto de Gerenciamento Integrado das Atividades Desenvolvidas em Terra na Bacia do São Francisco ANA/GEF/ PNUMA/OEA). Disponível em: www.ana.gov.br/gefsfbr/gefsf.

Neuman S.P. 1975. Analysis of pumping test data from aniso- tropic unconfined aquifers considering delayed yield. Water Resources Res., 11(2):329-342.

Ramos A.M. \& Silva F.F. 2002. Contribuição dos Mananciais Superficiais do Estado da Bahia para o Rio São Francisco. In: ABRH, Simpósio de Recursos Hídricos do Nordeste, 6, Maceió, CD-ROM.

Santana A.G. de, Cardoso E.R., Silva F.F. da \& Pereira J.S. 2002. Metodologia para Controle das Outorgas de Direito de Uso da Água em Bacias Hidrográficas. In: ABRH, Simpósio de Recursos Hídricos do Nordeste, 6, Maceió, CD-ROM.

Schuster H.D.M, Silva F.F., Teixeira S.L., Batista L.H.G. \& Freitas W.A. 2002. Estudos Hidrogeológicos do Aqüífero Urucuia no Oeste baiano para Obtenção de Parâmetros nas outorgas de mananciais Subterrâneos. In: ABAS, Congresso Brasileiro de Águas Subterrâneas, 12, Santa Catarina, CD-ROM.

Schuster H.D. 2003. Modelagem de Fluxo Subterrâneo com vistas à definição de parâmetros para outorgas de mananciais subterrâneos na bacia hidrográfica do rio dos Cachorros - Oeste do estado da Bahia. Projeto rio dos Cachorros e Anexos. 113 p.

Silva F.F, Neto A.V.L, Cardoso. E.R. \& Schuster H.D.M. 2005. Aplicação da modelagem matemática no uso conjunto água superficial e subterrânea para a gestão de recursos hídricos no oeste do estado da Bahia. In: ABRH, Simpósio de Recursos Hídricos da Amazônia, 2, Palmas.

Silva F.F., Neto A.V.L, Santana A.G. de \& Ribeiro C.A.O. 2002. Estudos de Casos na Estimativa da Vazão de Referência para Outorga do Direito de Uso da Água no estado da Bahia. In: ABRH, Simpósio de Recursos Hídricos do Nordeste, 6, Maceió, CD-ROM.

Manuscrito CSF-14

Submetido em 31 de maio de 2006 Aceito em 01 de março de 2007 